\title{
Reliability measure of the rib cage deformity by a postural assessment software in patients with adolescent idiopathic scoliosis
}

\section{Medida da Confiabilidade da Deformidade da Caixa Torácica por um Software de Avaliação Postural em Pacientes com Escoliose Idiopática do Adolescente}

\author{
Bruna Marques de Almeida Saraiva ${ }^{1}$ \\ (D) https://orcid.org/0000-0002-9539-5089 \\ Thais Moraes de Vieira ${ }^{1}$ \\ (i) https://orcid.org/0000-0002-3995-7091 \\ Anderson Sales Alexandre ${ }^{1}$ \\ (iD) https://orcid.org/0000-0003-1907-650X \\ Geferson da Silva Araújo \\ (D) https://orcid.org/0000-0002-0554-6358 \\ Evandro Fornias Sperandio ${ }^{1}$ \\ (D) https://orcid.org/0000-0002-8580-458X \\ Victor Zuniga Dourado ${ }^{1}$ \\ (iD) https://orcid.org/0000-0002-6222-3555 \\ Liu Chiao $\mathrm{Yi}^{1}$ \\ (D) https://orcid.org/0000-0003-0202-2337 \\ Milena Carlos Vidotto ${ }^{1}$ \\ (D) https://orcid.org/0000-0003-2879-6541
}

Abstract - Adolescent idiopathic scoliosis (AIS) is a three-dimensional deformity of the spine that generates changes in the biomechanics of the rib cage. Digital photogrammetry enables the recording of subtle changes and the interrelationship between parts of the human body that are difficult to measure by other means. The aim of this study was to create angles and thoracic distances and to evaluate the interobserver and intraobserver reliability of these measurements using the Software de Avaliação Postural (SAPO) in patients with AIS. This cross-sectional study evaluated 30 individuals aged between 11 and 18 years with AIS. We used SAPO with the thoracic markers in the form of angles (A) and distances (D) with involves structures like acromion, manubrium, xiphoid process, lower angle of the scapula, last false rib, anterior iliac spine process. Two experienced observers (A and B) analyzed the photos and all followed the same routine of analysis. Intraobserver and interobserver reproducibility was assessed by the Bland-Altman plot and intraclass correlation coefficient (ICC), while intraobserver and interobserver reliability was assessed by the T-Test and Wilcoxon's Test. A high repeatability index was obtained among the evaluations, with twelve of the sixteen variables considered as reliable in all statistical tests. The interobserver analyzes presented excellent correlation coefficients (ICC), showing good reliability for six of the sixteen variables proposed. The SAPO method presented good reproducibility and reliability for most of the thoracic markers created, showing that photogrammetry may be a complementary tool in the evaluation of thoracic alterations in patients with AIS.

Key words: Adolescent; Scoliosis; Software; Rib cage.

Resumo - A escoliose idiopática do adolescente (EIA) é uma deformidade tridimensional da coluna que gera alteraçôes na biomecânica da caixa torácica. A fotogrametria digital permite o registro de mudanças sutise a inter-relação entre partes do corpo humano que são difíceis de medir por outros meios. Objetivou-se criar ângulos e distâncias torácicas e avaliar a confiabilidade interobservador e intraobservador dessas medidas utilizando o Software de Avaliação Postural (SAPO) em pacientes com EIA. Este estudo transversal avaliou 30 individuos com idades entre 11 e 18 anos com EIA. Utilizamos o SAPO com os marcadores torácicos na forma de ângulos $(A)$ e distâncias $(D)$, envolvendo estruturas como: acrômio, manúbrio, processo xifóide, ângulo inferior da escápula, última costela falsa, processo da espinha ilíaca anterior. Dois observadores experientes $(A$ e $B$ ) analisaram as fotos e todos seguiram a mesma rotina de análise. A reprodutibilidade intraobservador e interobservador foi avaliada pelo gráfico de Bland- Altman e coeficiente de correlação intraclasse (CCI), enquanto a confiabilidade intraobservador e interobservador foi avaliada pelo Teste Te Teste de Wilcoxon. Um alto indice de repetibilidade foi obtido entre as avaliaçôes, com doze das dezesseis variáveis consideradas confúveis em todos os testes estatísticos. As análises interobservadores apresentaram excelentes coeficientes de correlacão (ICC), mostrando boa confiabilidade para seis das dezesseis variáveis propostas. O método SAPO apresentou boa reprodutibilidade e confiabilidade para a maioria dos marcadores torácicos criados, mostrando que a fotogrametria pode ser uma ferramenta complementar na avaliação de alterações torácicas em pacientes com EIA.

Palavras-chave: Adolescente; Caixa torácica; Escoliose; Software
1 Universidade Federal de São Paulo. Santos, SP. Brasil

Received: October 23, 2018 Accepted: August 30, 2019

How to cite this article

Saraiva BMA, Vieira TM, Alexandre AS, Araújo GS, Sperandio EF, Dourado VZ, Yi LC, Vidotto MC. Reliability measure of the rib cage deformity by a postural assessment software in patients with adolescent idiopathic scoliosis. Rev Bras Cineantropom Desempenho Hum 2020, 22:e59870. DOl: http://dx.doi. org/10.1590/1980-0037.2020v22e59870

Copyright: This work is licensed under a Creative Commons Attribution 4.0 International License. 


\section{INTRODUCTION}

Adolescent idiopathic scoliosis (AIS) is characterized by a structural lateral curvature of at least $10^{\circ}$ measured by the Cobb method and spinal rotation in a frontal spine radiograph, combined with anterior trunk flexion asymmetry ${ }^{1}$. The AIS is prevalent in female patients and the most common deformity is the right upper thoracic curve ${ }^{2}$.

Scoliosis brings harmful consequences to the postural axis of the individual, resulting in asymmetries and changes in tone, leading to severe deformities with cardiopulmonary impairment ${ }^{3}$. The curve tends to increase until the cessation of skeletal growth, with a worse prognosis for thoracic curves due to the rotation of the rib cage and the consequent effect on respiratory and cardiovascular system ${ }^{4}$.

The spine and ribs work together efficiently in breathing as a dynamic biomechanical structure. When the chest is affected by a significant deformity, the dynamics of this system change, interfering with normal breathing and lung performance ${ }^{5}$. Deformities should be evaluated by a combination of parameters such as vertebral rotation, chest wall deformities and possible limitations of respiratory muscles that, when combined, distort chest mechanics and cause lung impairment in different degrees ${ }^{6-8}$. The Cobb method measures the scoliosis angle from a full spine radiography. For its objectivity, Scoliosis Research Society considers the Cobb method as the best form of evaluation to determine the severity of scoliosis?.

Currently, the technological development allowed the use of some photographic techniques to evaluate musculoskeletal conditions. The digital photogrammetry is a new way of assessing the spine and rib cage deformities that can be performed as often as necessary without harmful effect. This is a non-invasive computerized photographic method, with easy application and reliable reproducibility ${ }^{10}$. This method enables the recording of subtle changes and the interrelationship between parts of the human body that are difficult to measure by other means and allows the assessment of changes in body segments using angular and linear measurements ${ }^{11}$.

Among the software available for postural analysis by photogrammetry, we highlight the Software de Avaliação Postural (SAPO), a free program available on the internet, developed by researchers from the University of São Paulo ${ }^{12}$ and some studies have evaluated the effectiveness of SAPO use $^{13-15}$. To our knowledge, few studies evaluated chest wall changes using this software. In the first, the authors showed distinct angles with excellent intraobserver and interobserver reproducibility and good accuracy to detect thoracic alterations in children born prematurely. The others studies showed the correlation between exercise capacity, lung function, and chest wall geometry ${ }^{10,16,17}$.

Despite the increasing number of studies using photogrammetry ${ }^{10,12-17}$, there is still no standardization on angles used to verify chest wall changes.

Considering that spinal deformity in AIS cause chest wall alterations and the lack of studies that quantify these postural deviations; the aim of 
this study is to create thoracic markers in the form of angles and distances and evaluate the reliability of the Software de Avaliação Postural (SAPO) in patients with adolescent idiopathic scoliosis.

\section{METHOD}

A cross-sectional study carried out in 30 AIS patients from the spine outpatient clinic of a local hospital. We evaluated patients of both genders in preoperative period, aged between 11 and 18 years. We excluded patients with previous respiratory diseases. All participants in the study signed the consent form and free and informed consent. The Research Ethics Committee of the Federal University of São Paulo (n. 1283/11) approved in the present research.

\section{Photography}

The subjects remained in orthostatic position at a previously marked location, at a distance of $3.0 \mathrm{~m}$ from the camera. The digital camera (SONYCyber Shot, DSC-W300) was positioned parallel to the floor, with the help of a professional tripod placed at the half height of the volunteer. We put a plumb line on the ceiling of the evaluation room with a one meter marking to calibrate the photos in an upright position. The photographs were taken in the anterior, left lateral, right lateral and posterior views. Participants were asked to wear two-piece bathing suits to allow the markers to be displayed.

An Ethyl Vinyl Acetate (EVA) mat was used so that the foot position was marked and rotated on each photo taken, while the camera and the tripod remained in the same situation.

\section{Anatomical points}

The anatomical points were marked on the skin with the fixation of Styrofoam balls of $25 \mathrm{~mm}$ in diameter using double-sided adhesive tape. The Figure 1 shows the points identified uni and bilateral. The anatomical points used were based on the SAPO protocol, except point $1^{10}$ and point 3,4 and 5 that were created by our research group. Two trained evaluators always performed both the marking of the anatomical points and the photographic record.

\section{Photo analysis through SAPO}

The photos were asses by two evaluators ( $\mathrm{A}$ and $\mathrm{B}$ ) experienced in handling the SAPO. The two evaluators followed the steps below.

Initially, patients were registered in the software, and then the calibration of the photos was performed to define the position of the photograph concerning the positioning of the camera and to set a scale. The definition of photography area is necessary so that the projection calculation of the gravity center of the support base is correct and so that the scanned positions points and the measurement of the distances between the points are given in centimeters and not in pixels. 
The analysis of the anatomical points obeyed the following routine: the opening of the photo, zoom of $75 \%$, image calibration from the plumb line and marking the anatomical points. After the photographs calibration, they were analyzed according to the linear and angular measurements between the previously demarcated anatomical points.

Angles (A) and distances (D) evaluated the rib cage changes (Figure 1). Except for the A4 angle, all the others angles and distances created were based on anatomical processes.

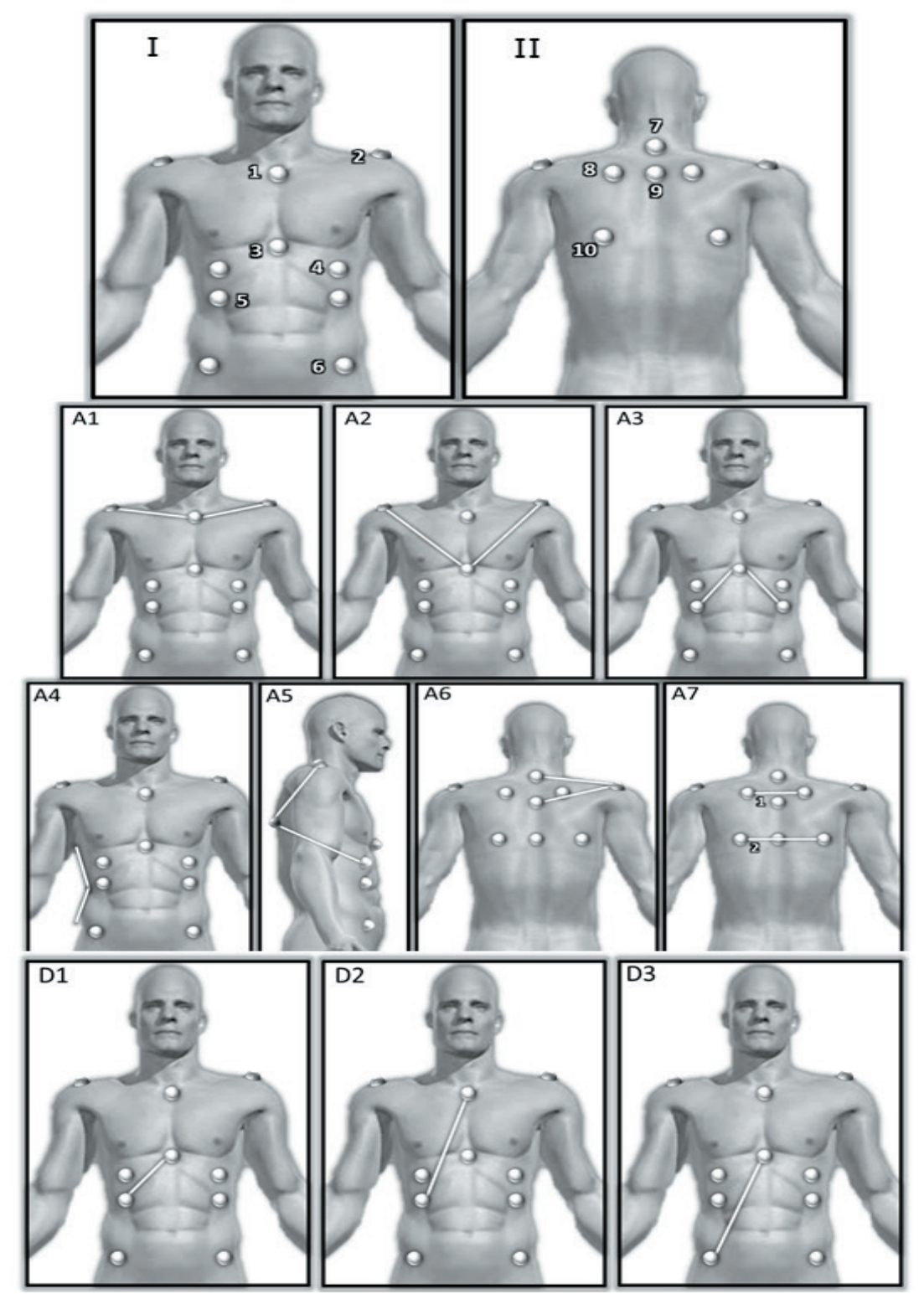

Figure 1. (I): 1. Manubrium of the sternum; 2. Acromial of the scapula; 3 . Xiphoid process of the sternum; 4. Inframammary region (half of the distance between the nipple and the last false rib); 5. Last false rib (intersection of the nipple line with the last false rib); 6 . Anterosuperior iliac spine (ASIS). (II): 7. C7 spiny process; 8 . Upper angle of the scapula; 9 . T3 spiny process; 10 . Lower angle of the scapula. A1. Right acromion / Manubrium / Left Acromion; A2. Right Acromion / Xiphoid Process / Left Acromion; A3. Last false right rib /Xiphoid process /Last false left rib; A4. Lateral deviation of her trunk; A5. Acromion /Lower angle of scapula /Inframamillary point A6. C7/ Acromion/T3. A7. Intersection of segments; D1. Xiphoid process / last false rib. D2. Manubrium / Last false rib. D3. Xiphoid process/Anterosuperior iliac spine. 
The A4 angle was measured by the deepest point of the waist and its top and bottom edges. For this reason, the measurement may suffer from the subjectivity of the evaluator. For the A4 angle analysis the tool "edge detector", available in SAPO, was used to facilitate the visualization of the body margins, to provide a more accurate and reliable analysis of this angle.

The entire process of photos analyzing was repeated by the evaluator A with an interval of one week to verify their repeatability, and by the evaluator B who performed the analysis.

\section{Statistical Method}

The descriptive analysis was express as the mean and standard deviation and frequency and percentage. The Bland-Altman plot was used to analyze and visualize the pattern of agreement between the repeated measures of the two evaluators.

The descriptive analysis was express as the mean and standard deviation and frequency and percentage. The Bland-Altman plot was used to analyze and visualize the pattern of agreement between the repeated measures of the two evaluators.

The reproducibility (evaluator A and B) was evaluated by the intraclass correlation coefficient (ICC). Reliability was assessed by t-Student and the Wilcoxon test, and $\mathrm{p}<0.05$ was considered statistically significant for both trials.

\section{RESULTS}

We selected 30 photos from the database of our research group. The chosen photos were from patients with mild, moderate and severe angulations by the Cobb method. We evaluated 25 girls (83\%) and 5 boys (17\%) with $14.2 \pm 2.2$ years, $1.59 \pm 0.09$ meters, $47.6 \pm 7.3$ kilograms. They presented values of the proximal thoracic Cobb angles of $28 \pm 11$ degrees; main thoracic of $58.5 \pm 16.6$ degrees and lumbar 38.3 \pm 11.8 .

The intraobserver analysis was based on the first and second evaluations of observer A (evaluation 1 and 2), while for interobserver analysis the first assessment of observer A and the only evaluation of observer B were used. The detailed measures of the variables evaluated by observers A (evaluetion 1 and 2) and B, were described in Table 1.

The reliability of the intraobserver and interobserver measures are described in Tables 1 and 2, respectively. Only the left A4 angle showed low intraobserver reliability, while in the interobserver evaluation the angle A1 and the left D1, D2 and D3 distances presented low reliability.

Intraobserver graphical concordance analyses (Bland-Altman plot) showed that angles: A1, A2, right A4, right and left A5, left A6, and all distances (D1, D2, and D3) of both sides showed good agreement. While the interobserver analyzes, the right angles A2, A3, A5, right and left A6 and D1 distance also obtained a good correlation.

Figures 2 show the Bland-Altman plots representing the angles and distances that were found to have a good correlation in both analyzes. 
Table 1. Descriptive measures of angles (A) and distances (D) expressed as mean and standard deviation

\begin{tabular}{|c|c|c|c|}
\hline Variable & Observer A & Observer A & Observer B \\
\hline & Evaluation 1 & Evaluation 2 & \\
\hline \multicolumn{4}{|l|}{ Angles $\left({ }^{\circ}\right)$} \\
\hline $\mathrm{A} 1$ & $176.03(10.31)$ & $175.77(10.21)$ & $176.68(10.09)$ \\
\hline A2 & $93.01(10.20)$ & $92.81(10.25)$ & $93.14(10.35)$ \\
\hline A3 & $84.93(13.80)$ & 85.06 (13.71) & $85.33(14.29)$ \\
\hline A4 right & $157.51(12.97)$ & $157.62(12.83)$ & $156(13.45)$ \\
\hline A4 left & $156.60(13.71)$ & $156.10(13.97)$ & $158.38(16.32)$ \\
\hline A5 right & 75.98 (8.31) & $75.85(8.41)$ & 75.91 (8.51) \\
\hline A5 left & $83.08(8.44)$ & $83.08(8.41)$ & $82.92(7.53)$ \\
\hline A6 right & $17.75(5.47)$ & $17.80(5.41)$ & $17.78(5.46)$ \\
\hline A6 left & $18.30(5.30)$ & $18.28(5.28)$ & $18.40(5.21)$ \\
\hline A7 & $5.11(3.89)$ & $5.15(4.14)$ & $5.29(4.02)$ \\
\hline \multicolumn{4}{|c|}{ Distances (cm) } \\
\hline D1 right & $11.80(1.79)$ & $11.81(1.75)$ & $11.85(1.76)$ \\
\hline D1 left & $11.74(1.73)$ & $11.75(1.68)$ & $11.82(1.77)$ \\
\hline D2 right & 24.78 (2.99) & $24.82(3.01)$ & $24.92(3.02)$ \\
\hline D2 left & $24.62(2.85)$ & $24.65(2.87)$ & $24.71(2.85)$ \\
\hline D3 right & $22.75(3.04)$ & $22.75(3.01)$ & $22.03(4.75)$ \\
\hline D3 left & $22.70(2.82)$ & $22.68(2.80)$ & $22.82(2.80)$ \\
\hline
\end{tabular}

Note. A1 (right acromion / manubrium / left acromion), A2 (right acromion / xiphoid / left acromion), A3 (last false right rib / xiphoid / last false left rib), A4 (lateral inclination of the trunk), A5 right and left (inframammary point / lower angle of scapula / acromion in right and left lateral views), A6 right and left (C7/acromion/T3), D1 right and left(Xiphoid - last false right rib on right and left side), right and left D2 (manubrium - last false rib on right and left side) e D3 right and left (xiphoid - right and left anterior superior iliac spine).

Table 2. Results of the concordance study among intraobserver analysis variables.

\begin{tabular}{lccc}
\hline Variable & ICC - IC95\% & $\begin{array}{c}\text { T-Test } \\
p\end{array}$ & $\begin{array}{c}\text { Wilcoxon Test } \\
\text { p }\end{array}$ \\
\hline Angle & & & \\
A1 & $0.99[0.98-0.99]$ & 0.203 & 0.428 \\
A2 & $0.99[0.99-0.99]$ & 0.150 & 0.416 \\
A3 & $0.99[0.99-0.99]$ & 0.237 & 0.346 \\
\hline A4 right & $0.99[0.98-0.99]$ & 0.695 & 0.673 \\
A4 left & $0.99[0.98-0.99]$ & 0.058 & $0.024^{\star}$ \\
\hline A5 right & $0.99[0.99-0.99]$ & 0.348 & 0.501 \\
A5 left & $0.99[0.99-0.99]$ & 0.956 & 0.873 \\
\hline A6 right & $0.99[0.99-0.99]$ & 0.516 & 0.263 \\
A6 left & $0.99[0.99-0.99]$ & 0.796 & 0.819 \\
\hline A7 & $0.98[0.97-0.99]$ & 0.773 & 0.917 \\
Distances & & & 0.922 \\
\hline D1 right & $0.99[0.99-0.99]$ & 0.912 & 0.675 \\
D1 left & $0.99[0.98-0.99]$ & 0.858 & 0.370 \\
\hline D2 right & $0.99[0.99-0.99]$ & 0.436 & 0.294 \\
\hline D2 left & $0.99[0.99-0.99]$ & 0.498 & 0.874 \\
\hline D3 right & $0.99[0.99-0.99]$ & 0.916 & 0.668 \\
\hline D3 left & $0.99[0.99-0.99]$ & 0.562 & \\
\hline
\end{tabular}

Note. ICC: Intraclass Correlation Coefficient, IC 95\%: Confidence interval, p: significance level. A1(right acromion / manubrium/left acromion), A2 (right acromion / xiphoid / left acromion), A3 (last right false rib / xiphoid / last false left rib), A4 (lateral inclination of the trunk), A5 right and left (inframammary point/lower angle of scapula/acromion in right and left side views), A6 right and left (C7/acromion/T3), D1 right and left (xiphoid - last left and right false rib), D2 right and left (manubrium -last left and right false rib), D3 right and left (xiphoid - right and left upper anterior iliac spine). ${ }^{*} \mathrm{p}<0.05$. 
Table 3. Results of the concordance study among the variables of the interobserver analysis.

\begin{tabular}{lccc}
\hline Variable & ICC - IC95\% & $\begin{array}{c}\text { T-Test } \\
p\end{array}$ & $\begin{array}{c}\text { Wilcoxon Test } \\
p\end{array}$ \\
\hline Angle & $0.98[0.97-0.99]$ & $0.020^{*}$ & $0.017^{*}$ \\
A1 & $0.99[0.98-0.99]$ & 0.550 & 0.600 \\
\hline A2 & $0.99[0.98-0.99]$ & 0.122 & 0.113 \\
\hline A3 & $0.94[0.87-0.97]$ & 0.070 & 0.120 \\
\hline A4 right & $0.82[0.66-0.91]$ & 0.288 & 0.388 \\
A4 left & $0.98[0.96-0.99]$ & 0.822 & 0.589 \\
\hline A5 right & $0.85[0.72-0.92]$ & 0.842 & 0.393 \\
\hline A5 left & $0.99[0.99-0.99]$ & 0.741 & 0.649 \\
\hline A6 right & $0.99[0.99-0.99]$ & 0.307 & 0.312 \\
\hline A6 left & $0.98[0.97-0.99]$ & 0.089 & 0.079 \\
\hline A7 & & & \\
Distances & $0.99[0.99-0.99]$ & 0.187 & 0.209 \\
\hline D1 right & $0.99[0.98-0.99]$ & $0.015^{*}$ & $0.024^{*}$ \\
D1 left & $0.99[0.99-0.99]$ & $0.003^{*}$ & $0.005^{*}$ \\
\hline D2 right & $0.99[0.99-0.99]$ & $0.034^{*}$ & $0.027^{*}$ \\
\hline D2 left & $0.59[0.30-0.78]$ & 0.286 & $0.036^{*}$ \\
\hline D3 right & $0.99[0.98-0.99]$ & $0.054^{*}$ & 0.060 \\
\hline D3 left & & & \\
\hline
\end{tabular}

Note. ICC: Coeficiente de Correlação Intraclasses, IC95\%: Intervalo de confiança, p: nível de significância. A1 (acrômio direito/manúbrio/acrômio esquerdo), A2 (acrômio direito/xifóide/acrômio esquerdo), A3 (última costela falsa direito/xifóide/última costela falsa esquerda), A4 (inclinação lateral do tronco), A5 direito e esquerdo (ponto inframamilar/ângulo inferior da escápula/acrômio nas vistas laterais direita e esquerda), A6 direito e esquerdo (C7/acrômio/T3), ) D1 direita e esquerda (xifóide - última costela falsa do lado direito e esquerdo), D2 direita e esquerda (manúbrio - última costela falsa do lado direito e esquerdo), D3 direita e esquerda (xifoide - ElAS direita e esquerda) $e^{*} p<0,05$.

\section{DISCUSSION}

The present study proposed to create thoracic angles and distances using the Postural Evaluation Software (SAPO) in patients with adolescent idiopathic scoliosis and to evaluate the inter and intraobserver reliability of these measures. The angles and distances that presented the best agreement, reproducibility and reliability were $\mathrm{A} 2$, right $\mathrm{A} 5$, left $\mathrm{A} 6$ and right $\mathrm{D} 1$.

In our study, we obtained an excellent classification for all intraobserver analyzes, with values between 0.98 and 0.99 , while in the interobserver analysis only left A5 was classified as very good (ICC $=0.85)$ and right D3 as not acceptable $(\mathrm{ICC}=0.59)$. All other angles and distances were also classified as excellent, with values between 0.98 and 0.99 , which shows an excellent result. According to some authors, the intraclass correlation coefficient (ICC) should be used in all the studies that aim to observe the agreement between the measurements obtained in photogrammetry analyzes, being on some occasions the most important test for such objective ${ }^{14,18}$.

For the $\mathrm{t}$ test and the Wilcoxon test, only the left angle A4 presented low reliability in the intraobserver analysis, while in the interobserver evaluation, the A1 angle and the left D1, D2 and D3 distances presented low reliability, with statistically significant differences. Some authors state that individuals who are very familiar and trained with the proposed measure tend to present greater consistency in repeated measures than 

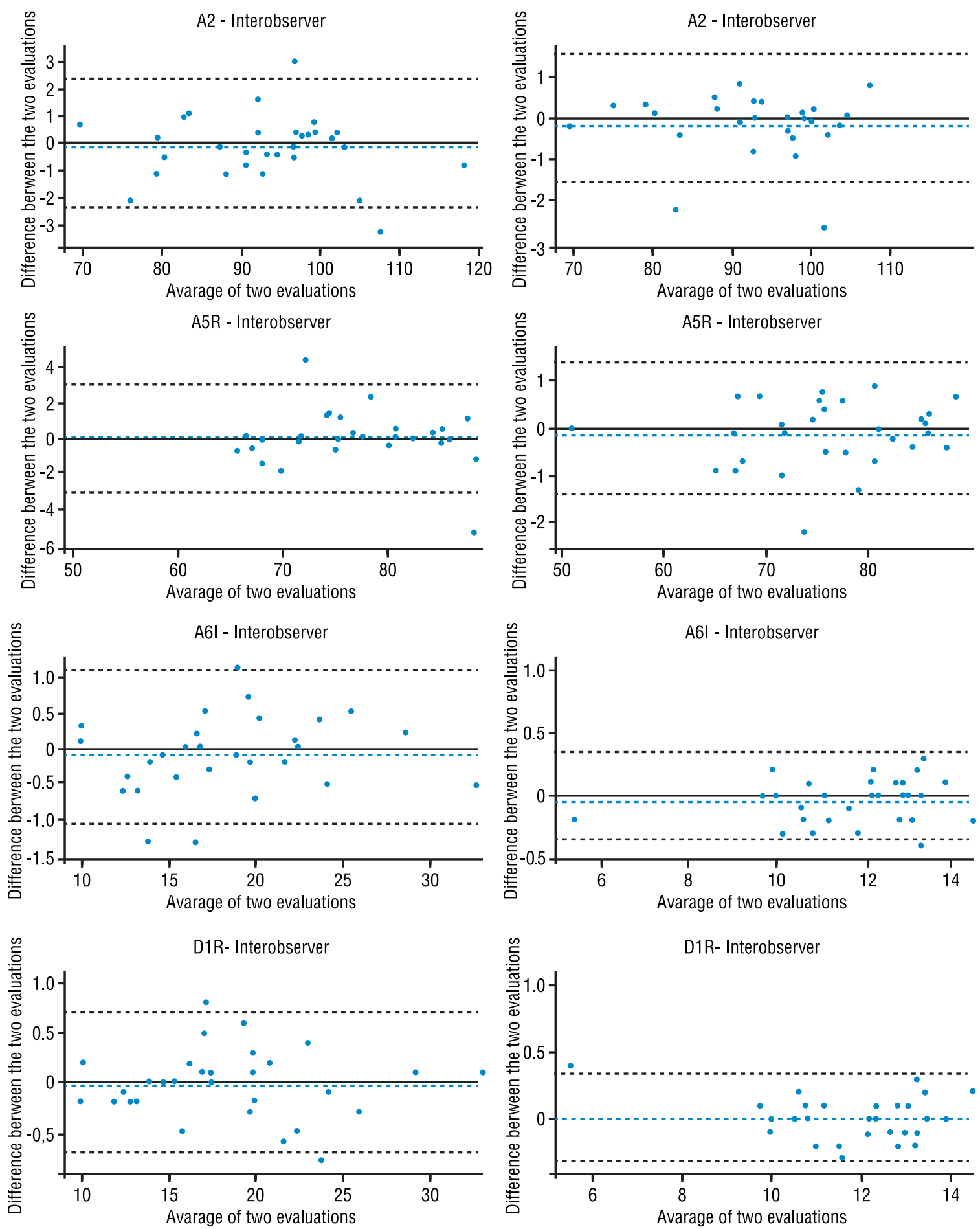

Figure 2. Bland Altman plot for variables: A2 (right acromion / xiphoid / left acromion); A5R (A5 right: inframamillary point / lower angle of scapula / acromion in right lateral view); A6L (A6 left: C7 / right acromion/ T3 and D1R (D1 right: xiphoid - last false right rib) in both analyzes.

the untrained ones. The greater the manipulation of instruments used in photogrammetry, the greater the credibility of the results ${ }^{14}$.

In the interobserver evaluation, the variables that demonstrated low reliability through the Bland-Altman chart were A3, right A4, left A6 and A7, while in the interobserver evaluation, the variables A1, right and left A4, left A5, A7 and all distances had a low agreement, except right D1. 
To present the results, we chose to insert the graphs that represented good reliability in both analyzes. Cardoso et al., in 2007, discusses that the reliability of measures can be influenced by factors such as the magnitude of variation between subjects and measures, systematic and random errors, lack of possibility of clinical interpretation and non-presentation of the values obtained $^{19}$. Beyond that, the Bland-Altman graph is a visual interpretation of the size and breadth of differences in measurements, errors or outliers.

Thus, for intraobserver reliability, twelve of the sixteen variables proposed had good results in the statistical analyzes, while for interobserver reliability, even with excellent ICCs, six of the variables achieved good results. Thus, our findings are in agreement with some studies that reported interobserver reliability being less than test-retest reliability for the indices of assessment of body posture ${ }^{15,20}$.

The angles A1 and A6 suggest inclination and rotation of the ribs and sternum, in addition to elevation of the shoulders. These angles use the acromion as an anatomical point, but depending on the rotation of the rib cage, the visualization of the styrofoam marker is compromised in the photos with anterior and posterior views, perhaps this is the reason the results are not favorable for these variables.

The A4 angle is difficult to measure, since it does not take into account anatomical points, but rather, the lateral lines of the trunk, which can induce failures in evaluations of different examiners. In another study, the results of the photogrammetry were observed with greater fidelity when using anatomical markers as reference, and not external markings, as a vertical line ${ }^{21}$.

The only variable of the study found in the sagittal plane was the A5 angle both sides, so it is not possible to state that the sagittal plane obtained good reliability since they were only two of the sixteen measures proposed, but only in the interobserver evaluation the left A5 angle obtained low reliability in statistical tests. Some studies have shown that the reliability index was lower in the sagittal plane ${ }^{18,22}$, because the image is a one-dimensional evaluation, whereas vertebral alterations are usually three-dimensional.

The A7 angle refers to the intersection of two straight lines, one passing through the upper angles and the other through the lower angles of the shoulder blades. As our sample was heterogeneous, with different degrees of scoliosis, the two straight lines that make up this angle presented very large variations and could be considered outliers for statistical analysis. Another study that evaluated the curvature of the spine through the photogrammetry method comparing with the Cobb method in a heterogeneous group found that the greater the inclination of the vertebral spine, the greater the rotation of the vertebral bodies, affecting the entire thoracic cavity, making its evaluation and analysis more difficult ${ }^{23,24}$.

For distances, the biggest challenge presented by the program is the impossibility of adjusting the point in the image, after already marking the photo. In this way, since the first marking is the one that counts for the distance, it is more difficult to accurately hit the center of the anatomical marker (half styrofoam sphere). 
The angular analysis of movement and body posture through the image has been the focus of physiotherapists and other professionals dealing with the area of human movement, and the evaluation of scoliosis through photogrammetry can be a relevant and simple way to analyze the spine, to detect deformities, to quantify in degrees the unevenness found and to be a useful tool for evaluating scoliosis ${ }^{25}$.

The SAPO is a validated instrument and several studies have demonstrated its reliability in different postural evaluations. One of themevaluated the inter- and intraobserver reliability of the angular measurements defined by SAPO's postural evaluation protocol and observed that, following their technical requirements, the quantification of the body segments through the SAPO protocol are valid and reliable when compared to goniometry ${ }^{12}$. Another study demonstrated that the proposed angles for the quantification of the postural asymmetries used by the SAPO protocol are satisfactorily reliable for the great majority of angular measurements studied when evaluated by different examiners in the same photographic record ${ }^{22}$.

One study showed that the SAPO program fulfilled the requirements of accuracy, objectivity and reliability and could be a useful tool for the evaluation of chest wall changes in prematurely born infants ${ }^{10}$. Thus, our work, despite using a method that has already been validated in other studies, sought to innovate by creating angles and distances, except A1, which was a contribution of the aforementioned study, to perform a specific postural evaluation not explored in the literature.

The SAPO protocol has advantages regarding the practicality of its use, the possibility of standardization of the measurements, the methodology for photogrammetric application and, consequently, the comparison between studies. In contrast, the disadvantage is related to the vertebral curves, which can be better visualized in profile and the protocol currently proposed by SAPO does not determine this evaluation and suggests additional analyzes for the sagittal plane ${ }^{22}$.

Based on the results of our study, it is possible to suggest that the Postural Evaluation Software (SAPO) is a reliable instrument in the assessment of the chest wall in patients with idiopathic adolescent scoliosis, especially angles A2, right A5, left A6 and distance right D1. Although there was no unanimity in the tests, it is important to note that high reliability coefficients (ICC) were observed for fourteen of the sixteen proposed measures, presenting a great value for the study. It is possible to affirm that the proposed evaluation can offer a quantitative documentation of this involvement, which are not offered by the clinical exams in a unique and exclusive way, besides providing a follow-up of the structural deformities of the trunk, being able to serve as supplementary information for follow-up and treatment of scoliosis.

\section{CONCLUSION}

The angles and thoracic distances, created to evaluate the intraobserver and interobserver reliability, using the Postural Evaluation Software (SAPO), 
in patients with idiopathic adolescent scoliosis showed a high repeatability index and maintained excellent correlation coefficients for the interobserver evaluation. Which at the junction of the Statistical analysis, resulted in good reliability in this evaluation for six of the sixteen variables proposed.

Thus, we suggest that this method can be used reliably in the assessment of chest wall changes, completing physical assessments, often subjective. Thus, it can contribute to decision-making, analysis of therapeutic interventions and monitoring the progression or regression of adolescent idiopathic scoliosis.

\section{COMPLIANCE WITH ETHICAL STANDARDS}

\section{Funding}

This research did not receive any specific grant from funding agencies in the public, commercial, or not-for-profit sectors. This study was funded by the authors.

\section{Ethical approval}

Ethical approval was obtained from the local Human Research Ethics Committee - Federal University of São Paulo and the protocol no.1283/11 was written in accordance with the standards set by the Declaration of Helsinki.

\section{Conflict of interest statement}

The authors have no conflict of interests to declare.

\section{Author Contributions}

Conceived and designed the experiments: MCV, ASA, TMV, EFS. Performed the experiments: ASA, TMV, BMAS, GSA, EFS. Analyzed the data: BMAS, MCV. Wrote the paper: BMAS, TMV, ASA, MCV, VZD, LCY.

\section{REFERENCES}

1. Cheung WY, Luk KDK. Classification of adolescent idiopathic scoliosis. Bone Jt 2013:1-4.

2. Huynh AM, Aubin CE, Rajwani T, Bagnall KM, Villemure I. Pedicle growth asymmetry as a cause of adolescent idiopathic scoliosis: A biomechanical study. Eur Spine J 2007;16:523-529.

3. Tsiligiannis T, Grivas T. Pulmonary function in children with idiopathic scoliosis. Scoliosis 2012;7(1):7.

4. Cheng JC, Castelein RM, Chu WC, et al. Adolescent idiopathic scoliosis. Nat Rev Dis Prim 2015;1:15030.

5. Grivas TB, Vasiliadis ES, Mihas C, Savvidou O. The effect of growth on the correlation between the spinal and rib cage deformity: implications on idiopathic scoliosis pathogenesis. Scoliosis 2007;2:11.

6. Alves VLDS, Stirbulov R, Avanzi O. Impact of a physical rehabilitation program on the respiratory function of adolescents with idiopathic scoliosis. Chest 2006;130(2):500-505.

7. Takahashi S, Suzuki N, Asazuma T, Kono K, Ono T, Toyama Y. Factors of thoracic cage deformity that affect pulmonary function in adolescent idiopathic thoracic scoliosis. Spine 2007;32(1):106-112. 
8. Saraiva BMA, Araujo GS, Sperandio EF, Gotfryd AO, Dourado VZ, Vidotto MC. Impact of Scoliosis Severity on Functional Capacity in Patients With Adolescent Idiopathic Scoliosis. Pediatr Exerc Sci 2018;30(2):243-250.

9. Schiller JR, Thakur NA, Eberson CP. Brace management in adolescent idiopathic scoliosis. Clin Orthop Relat Res. 2010;468(3):670-678.

10. Davidson J, Dos Santos AMN, Garcia KMB, Garcia KM, Yi LC, João PC, et al. Photogrammetry: An accurate and reliable tool to detect thoracic musculoskeletal abnormalities in preterm infants. Physiother 2012;98(3):243-249.

11. Watson AWS, Mac Donncha C. A reliable technique for the assessment of posture: Assessment criiteria for aspects of posture. J Sports Med Phys Fitness 2000;40:260-270.

12. Braz RG, Pedroso F, Castilo D, Carvalho GA. Confiabilidade e validade de medidas angulares por meio do Software para Avaliação Postural. Fisioter em Mov 2008;21(3):117-126.

13. Icn $\mathrm{S}, \mathrm{S} \mathrm{A}, \mathrm{Bwc} \mathrm{Q}$ et al. Reliability of photogrammetry in relation to goniometry for postural lower limb assessment. Rev Bras Fisioter 2007;11(5):411-417.

14. Ribeiro CL, Martins MN, Amaro LLDM, et al. Confiabilidade intra e interavaliador por fotogrametria para avaliação do ângulo poplíteo. ConScientiae Saúde 2012;11(3):438-445.

15. Ferreira EAG, Duarte M, Maldonado EP, Burke TN, Marques AP. Postural assessment software (PAS/SAPO): validation and reliabiliy. Clinics 2010;65(7):675-681.

16. Sperandio EF, Vidotto MC, Alexandre AS, Yi LC, Gotfryd AO, Dourado VZ. Exercise capacity, lung function and chest wall shape in patients with adolescent idiopathic scoliosis. Fisioter Mov 2015;185(3):563-572.

17. Saraiva BMA, Cristina Stella T, da Silva Araujo G, Fornias Sperandio E, Zuniga Dourado V, Carlos Vidotto M. Thoracic changes and exercise capacity in patients with adolescent idiopathic scoliosis. Fisioter Mov 2017;3030:209-217.

18. Iunes DH, Bevilaqua-Grossi D, Oliveira AS, Castro FA, Salgado HS. Análise comparativa entre avaliação postural visual e por fotogrametria computadorizada. Rev Bras Fisioter 2009;13(4): 309-15

19. Cardoso JR, Boer MC, Ito B, Oliveira R De, Kawano MM, Carregaro RL. Confiabilidade intra e interobservador da mensuração do ângulo de flexão anterior do tronco pelo método de Whistance. Fisioter Pesqui 2007;14(3):44-49.

20. Normand MC, Descarreaux M, Harrison DD, et al. Three dimensional evaluation of posture in standing with the PosturePrint: An intra- and inter-examiner reliability study. Chiropr Osteopat. 2007;15:1-11.

21. Dunk NM, Chung YY, Compton DS, Callaghan JP. The reliability of quantifying upright standing postures as a baseline diagnostic clinical tool. J Manipulative Physiol Ther 2004;27(2):91-96.

22. Souza JA, Pasinato F, Basso D, Corrêa ECR, da Silva AMT. Biofotogrametria confiabilidade das medidas do protocolo do software para avaliação postural (SAPO). Rev Bras Cineantropometria e Desempenho Hum 2011;13(4):299-305.

23. Antunes L, Silva E, Bocardo P, Daher D, Faggiotto R, Rugolo L. Efeitos da fisioterapia respiratória convencional versus aumento do fluxo expiratório na saturação de O2, freqüência cardíaca e freqüência respiratória, em prematuros no período pós-extubação. Rev Bras Fisioter 2006;10(1):97-103.

24. Saad KR, Colombo AS, Amado João SM. Reliability And Validity Of The Photogrammetry For Scoliosis Evaluation: A Cross-Sectional Prospective Study. Ethn Dis 2012;22(2):207-214.

25. Döhnert MB, Tomasi E. Validity of computed photogrammetry for detecting idiopathic scoliosis in adolescents. Rev Bras Fisioter 2008;12(4):290-297.

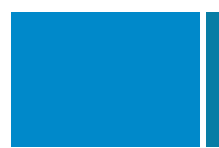

Corresponding author

Bruna Marques de Almeida Saraiva

136, Silva Jardim Street, Santos, SP, 11015-020, Brazil.

Email: brunalmeidam@gmail.com 